place by the ligament while the foetus grows, or is the process a mixed one? If the ligament of the ovary containing muscular fibres seizes the caudal extremity of the ovary and exerts traction upon it it is easy to understand how ovarian tissue may be dragged into its proper substance and be left behind after' removal of the ovary and ligation of the ovarian ligament. As the fotus grows traction may be made both ways upon the ovary as the uro-genital mesentery becomes stretched out. The upper portion of the urogenital mesentery, the ovario-pelvic ligament, may be considered to be dragged down from its original attachment to the diaphragm or to be left behind as the diaphragm recedes from it. In either case it would appear that some traction is made upon it in fotal life so that it would not be surprising to find Graafian follicles in the ovario-pelvic ligament as well as the ovarian ligament. I have myself seen on two occasions great elongation of the ovaries - in one instance amounting to three and three-quarter inches by measurement immediately after removal, without manipulation-not that the hypertrophy in these cases could be attributed to traction of the ovarian ligaments. To me, however, it is quite conceivable that traction may in some instances account for the presence of Graafian follicles within the ovarian ligaments.

The consideration of ovarian hernia throws little light upon the problem because the inguinal ligament is attached to the cornu of the uterus in such cases as in normal conditions, except that it may drag upon the uterine cornu. If the ovary were dragged into the inguinal canal by a true gubernaculum forming no connexion with the uterus but coming directly from the genital gland, as in the testis, it would be a very interesting fact, but this appears never to be the case. In congenital herniæ the tube generally accompanies the ovary into the sac--often together with an enterocele, as Langton has shown. It appears to be a true hernia or protrusion of the viscus into a patent or potentially datent diverticulum of peritoneum, as in femoral and obturator hernia. The whole subject of the relation of the ovary and ovarian tissue to the ligaments does not appear to have been worked out very fully. Works on veterinary anatomy and comparative anatomy hardly allude to it. I cannot but think that the matter is worthy of more attention than it has hitherto received.

Charles-street, W.

\section{A CASE OF SEPTATE UTERUS AND VAGINA; PREGNANCY IN THE RIGHT HALF; DELIVERY.}

\section{BY CLAYTON A. LANE, M.D. LOND.,} CAPTATN, I.M.S.

A BeNGali female, aged 25 years, was admitted into the Eden Hospital, Calcutta, on March 13th, 1901, for her confinement, she being in pain at the time. She stated that she began to menstruate at the age of 12 years, the flow since then having been regular, free, painless, and lasting for seven days. She had last menstruated in August, 1900. On examination the abdomen showed a swelling limited almost entirely to the right half; it reached to the rib margin above and disappeared into the pelvis below; its left margin, running from above downwards and to the left, crossed the middle line at the level of the umbilicus. The swelling was tense and the outlines of the child could only indistinctly be made out. On examining by the vagina there was a thick fleshy septum dividing the vagina into two lateral halves, each of which was as capacious as the other. With a finger in each half of the vagina two distinct external ora could be felt. The two halves of the cervix were firmly united and not moveable upon one another, nor could any anterior or posterior groove be made out in the cylindrical cervical mass. Vaginal examination gave no clue as to which half of the uterus contained the fœetus, but from the lateral deflection of the fundus to the right there remained little doubt that the child lay in that half, and that the left half formed part at least of the mass which lay to the left of the mid-line at the pelvic inlet. She had no discharge of blood and her pains disappeared, so she left hospital five days later. She was readmitted in labour on May $20 \mathrm{~h}, 1901$. It may be here stated as illustrating the value of histories given by natives
of India that she now said that her menstruation lasted rule only two days. She had been in labour for fire hours and on examination of the abdomen the uterine tumour still lay obliquely, the fundus being entirely to the right of the mid-line, and the left border crossing this two inches above the umbilicus. The lower segment, on the other hand, lay more to the left than to the right of the mid-line. On vaginal examination the septum between the two halves of the vagina was still intact for the lower inch, but above this it was torn through, so that when one finger was introduced into each balf of this passage they met beyond the remaining bar. Above this bridge of tissue was felt the intact bag of membranes inclosing the presenting part, which consisted of the breech and both feet lying in the first position. With each pain the child was forced down against, and directly impinged upon, the remains of the vaginal septum, so that this bridge of tissue formed a detinite barrier restricting the further progress of the child. It was accordingly cut through and each half clamped to stop some oozing which was taking place from the cut surfaces. The perineum was somewhat rigid and the vulval orifice was narrow. The pains being good, the membranes were ruptured and the case thereafter left to nature until the breech was widely distending the perineum. The forceps clamping the remains of the septum were then removed and the child's legs were brought down without traction being made on the body. Progress then ceased, the pains lessened markedly in frequency, and the legs became blue. The hand was accordingly introduced into the vagina and both arms were brought down; they were not extended and were released without difficulty, but the necessarily rapid introduction of the hand past the breech, which was already distending the perineum, caused rupture of the latter as far as the anterior edge of the sphincter ani. By extending the legs of the child over the mother's pubes the face was born and the child was enabled to breathe, although the vertex was retained in the passage for another minute. The child breathed satisfactorily. The placenta was expressed on account of slight bleeding. The cut edges of the septum were closed by continuous catgut sutures, one suture lying on the anterior and one on the posterior wall of the now single vagina. Examination showed the remains of the torn upper part of the vaginal septum. The rent had extended up to the cervical portion of the septum, reaching as far as the internal ora, so that there was now a single cervical, just as there was a single vaginal, cavity. When the finger was passed into the cervical cavity it impinged at the level of the junction of the body and cervix of the uterus upon the lower edge of that part of the septum which divided the body into two lateral halves. Into the left half it was just possible to pass the finger to its whole extent, the surrounding walls being in contact with it on all rides, while into the right half the finger entered easily and revealed a capacious cavity. The perineum was then sutured, a continuous catgut suture being used for the mucous membrane and four interrupted silkworm-gut sutures for the more superficial parts. Some oozing from the uterine cavity was checked by the intramuscular injection of 10 minims of ergotin. The patient's subsequent progress was satisfactory. Her temperature rose to $100 \cdot 6^{\circ} \mathrm{F}$. the same evening but fell to $98.4^{\circ}$ at midnight; the highest points touched subsequently were, on the second day $99.4^{\circ}$, on the third $99^{\circ} 2^{\circ}$, and on the fourth $100 \cdot 4^{\circ}$, after which it did not again rise above normal. The discharge followed the usual course and ceased on the eleventh dav. On the thirteenth day the perineum had quite healed and was of good depth. The torn septum had nearly disappeared, being only represented by a markedly visible median raphe, palpable as a firm cord, and continued on to the anterior and posterior surfaces of the vaginal cervix as a median red line. Except for this the cervix did not appear unusual. There was a single external os, patulous, about three-quarters of an inch wide, admitting the tip of the finger, which could tben just feel the persistent remains of the septum between the two halves of the cavity of the uterine body. On bimanual examination the body of the uterus was anteflexed. It appeared to be single, no groove being palpable on either surface or on the fundus. It was wider than normal from side to side but not from before backwards, and it was symmetrical, the two halves appearing to be of the same size. The pelvic cavity, as estimated by the finger in the vagina, did not appear to be wider from side to side than usual. The length of the intercristal 
diameter was 9.875 inches and that of the interspinous $7 \cdot 5$ inches.

Judging by the number of cases reported a septate uterus and ragina with pregnancy in one-half appears to be a far less common abnormality than is bifid or bicornute uterus, with or without a septate vagina associated with the same condition. So far as could be ascertained with the references at my disposal here there had only been two similar cases described in English literature up to the end of the year 1901, the date at which this note was originally written. One case was published in 1888. ${ }^{1}$ The woman was pregnant twice. In the first labour she was seen by Dr. Culpin and Dr. G. E. Herman. At this time the upper part of the vaginal septum was torn, the lower part remaining intact. In the second labour the remains of the vaginal septum were torn but it does not appear that the intercervical septum tore, for it is expressly stated that during labour the head could be pushed aside and the os (presumably the external os) of the unimpregnated side felt. On this occasion she was examined by Mr. W. H. Plaister and Dr. Herman. The second case is one described by Dr. Wallace. ${ }^{2}$ The left half of the uterus was the seat of pregnancy; it was hard to the feel, and the right half is described as feeling like a "muscular mass on a muscular cyst." The description of the labour was promised when it occurred but it does not seem to have been published. Recently two more cases have been described. Dr. Pery ${ }^{3}$ has reported in the Revue Mensuelle de Gynécologie, Obstétrique, et Pèdiatrique de Bordeaux a case of a labour at six months in which the right half of a septate uterus contained the fœtus. The condition of the uterus and its relations to the abdominal wall were almost exactly as described in the case now reported when she first came under observation with false labour pains. During lahour the lower third of the septum which was present between the two halves of the vagina was torn. There had been no menstrual hæmorrhage from the left half of the uterus during pregnancy, but a decidua seems to have been passed before Dr. Pery was summoned and was thrown away by the midwife. He is of opinion that pregnancy had also occurred in the left half. Lastly, in T'HE LANCET ${ }^{4}$ there is a full report by Dr. J. H. E. Brock of a case which he considers to be one of uterus didelphys because the two halves were moveable on one another and crossed one another diagonally. The patient went through one pregnancy and labour without anything occurring to suggest that there was any abnormality of the parts. She then consulted Dr. Brock for dyspareunia and on examination the septum dividing the vagina into two halves was discovered and removed. Two years later she became pregnant in the left half of the uterus, the abdominal condition at term being almost exactly that described in the case now published except for transposition, while vaginally the two halves of the cervix lay diagonally and the bodies were felt to cross one another. The labour passed off uneventfully.

In the case now reported no rectal examination was made with a view to determine whether the two halves of the uterus could be moved one on the other. This was not perceptible per vaginam, nor were the two halves of the uterus diagonally placed before, during, or after labour; and in addition it is to be noted that the thickness of the intrauterine portion of the septum, as indicated by the portion left untorn after labour, did not appear to be such as to suggest that it was made up of the loosely attached halves of a double uterus. All the facts appear to point to the conclusion that the case was one of septate uterus and vagina and not uterus didelphys. In conclusion, I am much indebted to Lieutenant-Colonel F. S. Peck, I.M.S., for his kind permission to publish this case.

Calcutta.

1 Brit. Med. Jour., vol. i., 1888, p. 955.

2 The London Medical Record and Recorder, 1890, p. 435.

3 Vide epitome, Brit. Med. Jour., vol. i., 1903, sec. 20.

4 THE IAANCET, Nov. 15th, 1902, p. 1319.

Russian Medical Students. - The Novoe Vremya says that in view of the war, the liberation of medical students at the Military Medical Academy will be advanced this year as it was last. The final examinations will begin in the first half of March and will close in the middle of May. In any case the number will be very small as they can be selected from only 70 students.

\section{Ollinital 算otes:}

MEDICAL, SURGICAL, OBSTETRICAL, AND THERAPEUTICAL.

\section{A CASE OF DEPRESSION OF THE LEFT PARIETAL BONE IN AN INFANT WITH MARKED PRESSURE SYMPTOMS.}

By D. Ashley Wilson, M.B., Ch.B. Glasg., HOUSE SURGEON (OUT-DOOR DEPARTMENI) TO GLASGOW MATERTITY HOSPI'TAX.

THE patient in the present case was a boy who was born at full term on Dec. 10th, 1904, the mother being a primipara and married. She was well developed and the pelvis showed no abnormality, the following being the measurements : intercristal diameter, ten inches; interspinous diameter, nine and a quarter inches; external conjugate diameter, seven and a half inches; and diagonal conjugate diameter, four and a half inches. After a labour in which the first and second stages lasted 13 hours the child was born somewhat precipitately, resulting in an incomplete tear of the perineum. The child, on inspection was found to have a marked depression of the left parietal bone, somewhat oval in shape, measuring three inches in length and two and a quarter inches across. It occupied the upper two-thirds of the bone. On Dec. 11th, 30 hours after birth, the child developed marked symptoms of cerebral irritation. The arms became flexed and rigid and there were constant twitchings of both hands and fingers but more especially on the right side. The feet showed twitching movements to a less extent. The head was drawn to the right side and there were present also twitchings of the eyes and mouth but no definite squint or abnormality of the pupillary conditions.

As the pressure symptoms showed no signs of improvement the following operation was performed on the evening of Dec. 12th, 24 hours after the commencement of the symptoms. A flap was reflected and the bone having been incised just below the lower border of the depression a periosteal elevator was introduced between the bone and the dura mater and the depression was raised gradually. The wound was then closed and a dressing was applied in the ordinary way. The symptoms gradually diminished until 35 hours after operation, when the child slept well, and since that time there has been no reappearance of the twitchings. The patient has made an uninterrupted recovery and on Dec. 22nd, when the dressing was removed, the wound was found to have healed by first intention.

I have to thank Dr. J. M. Munro Kerr, under whose care the mother and child were, for the facilities which he has afforded me and also to thank Dr. N. C. Rogers for permission to make extracts from the ward journal.

Glasgow.

\section{A CASE OF SEVERE COUGH AND LOSS OF WEIGHT DUE TO ROUND WORMS IN THE INTESTINE.}

\section{By Prosper St. Lieger Liston, L.R.C.P., L.R.C.S. Irel.}

THE following case is, I think, of sufficient interest to be recorded.

The patient was a boy, 13 years of age, who measured 4 feet 11 inches in height and weighed 36 pounds. He was brought to me months ago suffering from an intense earache. His mother told me he had been taken to several medical men who told him that he was "in consumption." He had had cough, expectoration, and night sweats, the expectoration being often blood-stained, and was wasted to an extraordinary degree. His temperature was $104^{\circ} \mathrm{F}$. His abdomen was enormously distended and painful, there was great diarrhœa, he had no appetite, ard very rarely had more than one hour's rest at night. The family history showed that two sisters had died from some vague stomach trouble. On examining his throat I found an intestinal worm with its head firmly wedged into the Eustachian opening and I had great difficulty in pulling is away, after which the boy experienced immediate relief. 